\title{
Dynamics of Transition Metal and their Application in Biomedical Industry
}

\author{
Pijush Malpaharia ${ }^{1}$ and S. K. Pandey ${ }^{2 *}$ \\ ${ }^{1}$ Department of Chemistry, ${ }^{2}$ Department of Botany, Jamtara College Jamtara-815351, \\ S.K.M. University, Dumka, Jharkhand, India \\ *Corresponding author
}

\section{Keywords}

Transition metal,

Periodic table,

Oxidation,

Coordination

compounds,

Multicomponent

reaction,

Biomedical industry

Article Info

Accepted:

18 January 2020

Available Online:

10 February 2020

\section{A B S T R A C T}

The transition metals are a group of metals that are found in the middle of the periodic table. The alkaline earth metals, beginning with beryllium are to the left and the boron group elements are to the right are termed as "transition element". There are more transition metals than any other groups in the periodic table. Transition metals have several general properties. They are harder and less reactive than the alkaline earth metals. They are also harder than the post transition metals. They make colorful chemical compounds with other elements. Most of them have more than one oxidation state. Like other metals, they are electrical conductors. Some of the transition metals are necessary for human health, such as iron, zinc, and chromium. Other elements in the transition metals can be harmful to our body, like cadmium and mercury. Other elements like gold or silver do not harm or help us. Only a few of the transition metals are colored; most of them are silvergray or silver-bluish. The oxidation activity of transition metals led to the recent development of drugs which are based on metals and are considered to be potential for pharmacological and therapeutic applications. This review emphasizes on preclinical pharmacological screenings like anti-microbial, anti-inflammatory and anti-tumor action of synthetic transition metal complexes. It concentrates primarily on a limited number of first row transition metal complexes and traces the pharmacological applications of these coordination compounds. In the first part, the nitrogen, oxygen and sulfur donor ligands chelating to transition metals used in metallo drugs are described. The second part describes the pre-clinical screenings viz., anti-microbial, anti-inflammatory and anti-tumor responses of the above coordination compounds incorporating these nitrogen, oxygen and sulfur donor ligands. This survey encourages further research in this field for biomedical industry.

\section{Introduction}

Transition metals are often highly reactive due to their strong propensity toward oxidation to more stable high-valent states. Harnessing these highly reducing complexes for productive reactivity is potentially powerful for $\mathrm{C}-\mathrm{C}$ bond construction, organic reductions, small-molecule activation and many other reactions that offer orthogonal chemo selectivity and region selectivity patterns to processes promoted by late transition metals. Ions of metal play important roles in different biological processes. The field of knowledge related to the application 
of inorganic chemistry to diagnosis of diseases and their therapy is medicinal inorganic chemistry [1]. Among the natural sciences, medicinal inorganic chemistry is still considered a rather young discipline which is contrary to the historically proven use of metals in pharmaceutical potions, which traces back to the ancient civilizations of Mesopotamia, Egypt, India, and China [2]. The introduction of metal ions binding components into a biological system for the treatment of diseases is one of the emerging fields of bioinorganic chemistry. A wide range of biological activities such as antibacterial, antifungal, antitumor and antiviral activities are exhibited by the nitrogen-containing organic compounds and their metal complexes. Transition metal complexes offer two distinct advantages as DNA-binding agents which often show distinct electrochemical or photophysical properties, thereby increasing the functions of the binding agent [3]. In fact, these peculiar features have fuelled the complexes to be used in different applications, from fluorescent markers to DNA foot printing agents and electrochemical probes [4].

Among the metal ions platinum and ruthenium ions are commonly explored as coordination centers of potential anticancer agents, [5]. They are most abundantly occuring trace elements present in biological systems together with iron [6]. Less toxic nature of these targeting metal ions can be further decreased when coordinated with the ligands particularly. Though there are so many ligands are available i.e. N-heterocycles (1,10 Phenanthroline, Bipyridine) and pyrazolones with an added benefit to their properties which is a major advantage in designing an ideal drug. Amino acids are the building blocks of our body and when the the drug is similar to that of the functions inside the body there is maximum chances of succeeding in designing a less toxic and efficient cheap drug. In addition to that, the $\mathrm{N}$-heterocycles and pyrazolones as ligands affect the environment of the complex in such a way that their lipophilicity increases which is a leading factor in designing a drug.

The method used for this review is mainly based on secondary data. It follows a descriptive study and focuses on creating a detailed picture by identifying, obtaining, describing and analyzing available documents, published government policies, lectures-statements by government leaders and other views related to the research problem. In order to compile this manuscript the works related to the transition metals used in biomedical industry from the important journals, magazines, survey materials, periodicals, reports, booklets, newspapers, books published in India and abroad were taken into consideration.

\section{Transition metals and biomedical industry}

There are a large number of chemicals used in biomedical industry. However, the chemicals which contain transition metals are of high therapeutic and curative value. Some of the common and effective chemicals are depicted below in brief:

\section{Bioactive chelating agents}

Aliphatic Schiff bases are relatively unstable and easily polymerizable in comparision to other aromatic Schiff bases [7]. Their derivatives represent one of the modest classes of biologically active agents which have been deeply studied during a search on new potential agents which are widely used for synthesis purpose [8]. These ligands have received much attention mainly due to their antimicrobial, anti-tuberculosis, antitumour activity, anticonvulsant, anti-inflammatory, anti-HIV, anthelmintic and cardiovascular activities and anti-carcinogenic properties [9]. 


\section{Amino acids}

Schiff bases derived from amino acids are found to be very effective metal chelators. Their metal complexes are models for a number of important biological systems [10]. They are the key intermediates in a number of metabolic reactions involving amino acids such as decarboxylation, transamination and racemization which are catalyzed by enzymes [11]. Synthetic ligands with longer chains are preferred for pharmacological purposes are another fact to be considered.

Amino acids can act as coordinating agents through their amino $\left(\mathrm{NH}_{2}\right)$ and carboxylate $\left(\mathrm{COO}^{-}\right)$groups [12]. For sulfur-containing amino acids, the $\mathrm{SH}$ group confers a more versatile coordination activity toward heavy metal ions. The $-\mathrm{SH}$ (sulfahydryl), $-\mathrm{NH}_{2}$ (amino) and $-\mathrm{COO}^{-}$(carboxylate) groups are the possible coordination sites for the complexation processes. Sequestration of toxic heavy metal ions and obtaining safer drugs or antidotes for metal poisoning [13] by complexation is a very promising field.

The uncontrolled movement of metal ions in the human body leads to the formation of reactive oxygen species such as superoxide anion radical $\left(\mathrm{O}_{2}{ }^{-} \cdot\right)$, singlet oxygen $\left({ }^{1} \mathrm{O}^{2}\right)$, hydrogen peroxide $\left(\mathrm{H}_{2} \mathrm{O}_{2}\right)$, and the highly reactive hydroxyl radical $\left({ }^{\circ} \mathrm{OH}\right)$. Thus they can oxidize the biochemical molecules thereby disturbing the homeostasis in an organism.

Recently, Several experiments have evaluated the efficiency of antimicrobial potential of 2nitrobenzaldehyde-glycine and 2nitrobenzaldehyde- methionine against the growth of bacteria in vitro [14].

\section{Pyrazolones}

Pyrazolones are a class of organic compounds which have been studied extensively due to their biomedicinal properties [15]. Pyrazolone is a five-membered lactam ring which contains two nitrogens and a ketone in the same molecule and is an active moiety in pharmacological activity such as antiinflammatory and analgesic agents [16].

It is an active moiety as the pharmaceutical ingredient, especially in non-steroidal anti inflammatory drugs (NSAID) and is used in the treatment of cancer, arthritis and other musculoskeletal and joint disorders. Scientists have recently synthesized a Schiff base complex of copper with 5-dimethyl-2-phenyl4-[(pyridin-2-ylmethylene)- amino]-1,2dihydro-pyrazol-3-one and investigated its DNA binding propensity, nuclease, radicalscavenging and anti-cancer cytotoxic activities [17].

\section{Nitrogen heterocycles}

They are one of the most important classes of ligands in coordination chemistry $[18,19]$. In addition, 1,10-phenanthroline has shown retardation of growth of a Sarcoma-37 tumor [20] and it inhibits the cell proliferation of Ehrlich ascites [21]. This will be more permeable through the cell membrane and eventually behave as carriers of antitumor agents [22, 23].

\section{Bipyridine}

2,2 '-bipyridine is a chelating component. The 2,2'-bipyridyl moiety has been extensively used as a chelating donor site within such bridging ligands due to its robust redox stability [24]. This allows ligands containing multiple 2,2'-bipyridine units to be synthesized and the interconnection of metal centres to be achieved with well-defined spatial arrangements. This has been directed towards the study of metal-metal interactions in supramolecular chemistry to study anioninteractions as sensors in new coordination 
materials and as structural and functional enzyme active site models [25].

\section{Mode of action of transition metal complexes}

The application of transition metals and its compounds in medicine dates back to millennia which provide an experimental evidence for the effectiveness of such metalbased therapeutics. The chelates of transition metal play a significant role in bio-inorganic chemistry and redox enzyme systems serve as the basis of models for active sites in biologically important compounds [26]. These metels have different coordination geometry, versatile redox, spectral and magnetic properties which are appropriate for designing non-porphyrinic metal-based PDT agents that could photo cleave DNA in visible light. The relationship between vibrant metals and cancer is a multifaceted issue which combines the expertise of bioinorganic chemists, pathologists, pharmacologists and oncologists. Redox-active metals generally form reactive oxygen species (ROS) and this ROS can be used to induce DNA cleavage. Moreover, it cures only limited spectrum of cancers and acquired resistance [27]. To defeat these limitations of cis-platin, less toxic and more effective metallo drugs like oxaliplatin and carboplatin have been developed. DNA is the storage place of cellular information that is accessed continuously for storing and dispensing information required for existence. It acts as the main intracellular target for those who thrive to develop a new drug for innumerable diseases, particularly cancer. It is significant for the function of several enzymes and proteins involved in energy metabolism, respiration and DNA synthesis, particularly cytochrome oxidase, superoxide dismutase (SOD), ascorbate oxidase and tyrosinase [28]. Copper is found to bind DNA with high affinity than any other divalent cation, thus promoting DNA oxidation. The copper complexes synthesized by Gup and Gokce are found to bind significantly to calf thymus DNA by both groove binding and intercalation modes and effectively cleave pBR322 DNA. Most common medicinal uses of transition metal complexes are as follows:

\section{Anticancerous agents}

Chemotherapy using chemical agents is one of the effective methods for the treatment of various cancers. With the increasing number of compounds synthesized as potential anticancer drugs, effective screening methods are needed for classification of these compounds according to their anticancer activities [29]. The increasing number of multi-drug resistant microbial pathogens hardened the treatment of infectious diseases that posed as an important and challenging problem. Despite the availability of a large number of antibiotics and chemotherapeutics, a substantial need for the development of new class of potent antimicrobial agents arose on account of the emergence of old and new antibiotic resistant bacterial strains. Thus, the heterocyclic compounds play a considerable role in designing a new class of structural entities of medicinal importance with new mechanisms of action [30]. The diverse pharmacological properties possessed by heterocyclic compounds are the well known antimalarial, antimicrobial, antiinflammatory, anticancer, analgesic and anticonvulsant. The superoxide dismutases (SODs) known as metallo enzymes are able to keep the concentration of superoxide radicals in convenient low limits and thus, they can protect cells against an oxidative damage [31]. Recently it has been found that reactive oxygen species, such as the superoxide radical or hydrogen peroxide are important regulators of apoptosis [32]. Particularly, $\mathrm{H}_{2} \mathrm{O}_{2}$ is implicated as a mediator of the cell death. The cellular damage caused by $\mathrm{H}_{2} \mathrm{O}_{2}$ is due to the 
hydroxyl radical production that results from the reaction of $\mathrm{H}_{2} \mathrm{O}_{2}$ with transition metal ions [33].

\section{Anti-microbial agents}

The latest review focuses on the crisis of decrease in quinolone drug absorption when consumed simultaneously with magnesium or aluminium antacids. The work was emphasized on crystal structures of quinolone-metal compounds and their antimicrobial activities [34]. The reason for such behaviour is proposed to be the chelate bonding of the quinolone to the metal. The complex $\left[\mathrm{Cu}(\mathrm{cx})_{2}\right] .2 \mathrm{H}_{2} \mathrm{O}$ (where $\mathrm{cx}=$ cinoxacin) was screened for activity against several bacteria [minimal inhibitory concentration (MIC) values] showing the same antimicrobial activity as the free ligand. The complexes were screened for antimicrobial activity against various bacterial and fungal species viz., $E$. coli, $K$. pneumoniae, $P$. aeruginosa, $S$. aureus, A. niger and $C$. albicans by disc diffusion method. The $\mathrm{Cu}$ complex exhibited the highest zone of inhibition against the bacterial species viz. $K$. pneumoniae $(12 \mathrm{~mm})$ and $P$. aeruginosa $(11 \mathrm{~mm})$. The $\mathrm{Ni}$ mixed ligand complex exhibited a higher zone of inhibition against E. coli $(12 \mathrm{~mm})$ and $\mathrm{Zn}$ complex exhibited a higher zone of inhibition against Streptomyces. aureus $(12 \mathrm{~mm})$ [35]. From the above experiments it was concluded that among the four mixed ligand metal complexes, $\mathrm{Cu}$ mixed ligand metal complex showed higher antibacterial activity. In the case of antifungal activity, Co complex showed the higher zone of inhibition against the fungal species $C$. albicans $(13 \mathrm{~mm})$ and Ni complex showed higher activity against $A$. niger $(8 \mathrm{~mm})$. Overall, the antimicrobial activity of the complexes is in the following order: $\mathrm{Cu}>\mathrm{Co}>\mathrm{Ni}>\mathrm{Zn}$. The dominance of the metal complexes may possibly be as a result of increased lipophilic nature of the complexes attributed to chelation and heteroatoms present in the ligand moiety $[36,37,38]$.

\section{Anti-tumor agents}

There are several reports available about the ternary copper complexes, that are synthesized by the combination of a bidentate $\mathrm{N}$-donor heterocyclic ligand (phen, bpy or their substituted derivatives) and other synthetic co-ligands (i.e., salicylic acid, tetracycline derivatives, terpyridine, or imidazolidine-2-thione), with remarkable in vitro cytotoxicity towards the human cancer cell lines [39].. However, none of these dealt with the directed synthesis of mixed ligand copper coordination compounds containing flavonoid-inspired co-ligands. Lately, Rajendiran et al., (2007) have found that efficient self-activated DNA cleavage and cytotoxic effects toward L1210 murine leukemia and A2780 human ovarian carcinoma cell lines can be brought out by the complex [Cu (pyrimol) $\mathrm{Cl}]$, synthesized by them $[40,41]$. Harding and his co-worker have synthesized bis ( $75-(3,4-$ dimethoxybenzyl) cyclopentadienyl)-vanadium dichloride complex. Further in vitro and in vivo work revealed that $\mathrm{V}(\mathrm{IV})$ organometallic compounds exhibit significant anti-tumor properties with vanadocene dichloride being one of the most promising among metallocenes[42,43]. By comparing the cytotoxicity with that of the conventional standard cisplatin, they found that the complexes exhibited excellent activity in both the cancer cell lines. However, the cytotoxic activity of complexes against human breast cancer cell line stood higher than that of skin carcinoma cell line $[44,45]$.

\section{Anti-inflammatory agents}

The protective response of an organism, when treated by a noxious stimulus is known as inflammation. Such inflammatory conditions lead to rheumatic diseases. It is a part of the 
complex biological response of vascular tissues to harmful stimuli such as pathogens, damaged cells and irritants. Recent experiments revealed that 3,5diaminodiamido- 4-oxahexacyclododecane (cageL) can survive in vivo through a demonstration by speciation calculations using blood plasma model and animal biodistribution experiments, which is due to the stability in lipophilic conditions [46, 47]. In pursuit of developing better copper based anti-inflammatory drugs which can be administered orally, intravenously or even transdermally, they have designed and synthesized two ligands, N, NO-di (aminoethylene)- 2,6pyridinedicarbonylamine (L1) and bis-(N, Ndimethylethyl)-2,6- pyridinedicarboxamide (L2). L1 and L2 both have pyridyl groups which are found in most of the non-steroidal anti-inflammatory drugs (NSAIDs) [48]. A class of quinoline based compounds has been explored and found to have the ability to inhibit platelet-activating factor (PAF) synthesis which also contributes to antiinflammatory properties [49]. The role of copper in the pathology of inflammation emphasizes a lot of evidence [50]. The thorough investigation of copper complexes with different ligands together with antiinflammatory drugs and of the copper containing enzyme super oxide dismutase (SOD) brought to light the various therapeutic value of copper which is concluded to be an exogenous anti-inflammatory agent. Scientists have explored a series of Schiff bases derived from 2-mercapto-3-formyl quinoline/2hydroxy-3-formyl quinoline with 2,6diaminopyridine (DAP) and their corresponding $\mathrm{Co}$ (II), $\mathrm{Ni}$ (II), $\mathrm{Cu}$ (II) and $\mathrm{Zn}$ (II) complexes for their anti-inflammatory activity. The $\mathrm{Cu}$ (II) complexes showed the highest biological activities amongst the compounds tested [51].

A series of potential anti-inflammatory agents that are Co (II) complexes and bearing the
NSAID mefenamic acid ligand have also been investigated [52]. Mefenamic acid is found to act as a deprotonated monodentate ligand. It is coordinated to the Co (II) ion through its carboxylato oxygen atom, forming octahedral $\left[\mathrm{Co}(\mathrm{mef})_{2}(\mathrm{MeOH})_{4}\right]$ or $\left[\mathrm{Co}(\mathrm{mef})_{2}(\mathrm{MeOH})_{2}\left(\mathrm{~N}^{\wedge} \mathrm{N}\right)\right]$ (where mef $=$ mefenamic acid and $\mathrm{N}^{\wedge} \mathrm{N}=2,2^{\prime}$-bipyridine, 1,10-phenanthroline or (pyridine) $)_{2}$ ) complexes which is in accordance with the physicochemical and spectroscopic data. In later studies, $\mathrm{Cu}$ (II) complexes of mefenamic acid, naproxen, diclofenac, diflunisal and flufenamic acid, Co (II) complexes of naproxen and tolfenamic acid, and Mn (II) complexes of tolfenamic acid have been reported by the researchers that showed antiinflammatory activity[53].

Conclusions and future directions as follows:

The application of bioinorganic chemistry to medicine is a rapidly developing field. Novel therapeutic and diagnostic metal complexes are now having an impact on medical practice. Advances in bioinorganic chemistry are important for improving the design of compounds to reduce toxic side-effects and understand their mechanisms of action. This review reveals that the pharmacologically interesting metals such as copper, cobalt, nickel and zinc could be a suitable strategy to develop novel therapeutic tools for the biomedical industry.

\section{Acknowledgements}

The authors express their heartfelt thanks to the Head of the Department of Chemistry, Viswa Bharati, Santiniketan for their constant encouragement.

\section{References}

1. Aakeröy CB, Champness NR, Janiak C (2010) Recent advances in crystal engineering. Cryst Eng Comm 12: 22-43. 
2. Alessio E (2011) Bioinorganic Medicinal Chemistry(1stedn.), Wiley-VCH: Weinheim, Germany.

3. Ali AQ, Teoh SG, Salhin A, Eltayeb NE, Ahamed MBK, et al., (2014) Synthesis of platinum (II) complexes of isatin thiosemicarbazones derivatives: In vitro anti-cancer and deoxyribose nucleic acid binding activities. Inorganica Chimica Acta 416: 235-244.

4. Ang WH, Dyson PJ (2006) Classical and Non-Classical Ruthenium-Based Anticancer Drugs: Towards Targeted Chemotherapy. Eur J Inorg Chem 2006: 4003-4018.

5. Arayne S, Sultana N, Haroon U, Mesaik MA (2009) Synthesis, characterization, antibacterial and anti-inflammatory activities of enoxacin metal complexes. Bioinorg Chem Appl.

6. Bhat SS, Kumbhar AA, Heptullah H, Khan AA, Gobre VV, et al., (2011) Synthesis, electronic structure, DNA and protein binding, DNA cleavage, and anticancer activity of fluorophore-labeled copper(II) complexes. Inorg Chem 50: 545-558.

7. Booth NH, Mcdonald LE (1988) Veterinary pharmacology and therapeutics (5thedn.), Iowa State University Press, Ames.

8. Casini A (2012) Exploring the mechanisms of metal-based pharmacological agents via an integrated approach. J Inorg Biochem 109: 97-106.

9. Cechinel Filho V, Corrêa R, Vaz Z, Calixto JB, Nunes RJ, et al., (1998) Further studies on analgesic activity of cyclic imides. Farmaco 53: 55-57.

10. Chandra S, Vandana, Kumar S (2015) Synthesis, spectroscopic, anticancer, antibacterial and antifungal studies of $\mathrm{Ni}(\mathrm{II})$ and $\mathrm{Cu}(\mathrm{II})$ complexes with hydrazine carboxamide, 2-[3-methyl-2-thienyl methylene]. Spectrochim Acta A Mol Biomol Spectrosc 135: 356-363.

11. Chohan ZH, Supuran CT, Scozzafava A (2005) Metal binding and antibacterial activity of ciprofloxacin complexes. J Enz Med Chem 20: 303-307.

12. Cleare MJ, Hydes PC (1980) Metal Ions in Biological Systems, Sigel H(eds.), Dekker, New York, p: 11.
13. Devi J, Batra N (2015) Synthesis, characterization and antimicrobial activities of mixed ligand transition metal complexes with isatin monohydrazone Schiff base ligands and heterocyclic nitrogen base. Spectrochim Acta A Mol Biomol Spectrosc 135: 710-719.

14. Dhanaraj CJ, Johnson J (2015) Quinoxaline based bio-active mixed ligand transition metal complexes: Synthesis, characterization, electrochemical, antimicrobial, DNA binding, cleavage, antioxidant and molecular docking studies. Journal of Photochemistry and Photobiology B: Biology 151: 100-109.

15. Dimiza F, Papadopoulos AN, Tangoulis V, Psycharis V, Raptopoulou CP, et al., (2010) Biological evaluation of non-steroidal antiinflammatory drugs-cobalt(II) complexes. Dalton Trans 39: 4517-4528.

16. Elsayed SA, Jean-Claude BJ, Butler IS, Mostafa SI (2012) Synthesis, structural characterization and anticancer activity of some new complexes of 6-amino-4hydroxy-2-thiopyrimidine. J Mol Struct 1028: 208-214.

17. Farrell NP (1999) Uses of Inorganic Chemistry in Medicine (1st edn.), Royal Society of Chemistry, Cambridge, UK.

18. Fraústo da Silva JJR, Williams RJP (2001) The Biological Chemistry of the Elements (2ndedn.), Oxford University Press, Oxford.

19. Gudasi KB, Vadavi RS, Shenoy RV, Patil SA, Nethaji M (2006). Crystal Structure of 2-thiophene-2-yl-3 (thiophene-2carboxylideneamino)-1,2dihydroquinazolin-4(3H)-one and the Synthesis, Spectral and Thermal Studies of its Transition Metal (II) Complexes. Transit Met Chem 31: 374-381.

20. Gwaram NS, Ali HM, Khaledi H, Abdulla MA, Hadi AH, et al., (2012) Antibacterial evaluation of some Schiff bases derived from 2-acetylpyridine and their metal complexes. Molecules 17: 5952-5971.

21. Hambley TW (2007) Developing new metal-based therapeutics: challenges and opportunities. Dalton Trans, pp: 4929-4937.

22. Hannon MJ (2007) Metal-based anticancer drugs: From a past anchored in platinum 
chemistry to a post-genomic future of diverse chemistry and biology. Pure Appl Chem79: 2243-2261.

23. Harding MM, Mokdsi G (2000) Antitumour metallocenes: structure-activity studies and interactions with biomolecules. Curr Med Chem 7: 1289-1303.

24. Holder AA (2012) Inorganic pharmaceuticals. Annu Rep Prog Chem, Sect A: Inorg Chem 108: 350-368.

25. Hoonur RS, Patil BR, Badiger DS, Vadavi RS, Gudasi KB, et al., (2010) Transition metal complexes of 3-aryl-2-substituted 1, 2-dihydroquinazolin-4 $(3 \mathrm{H})$-one derivatives: New class of analgesic and anti-inflammatory agents. Eur J Med Chem 45: 2277-2282.

26. Jaouen G (2006) Bioorganometallics: Biomolecules, Labeling, Medicine. Wiley$\mathrm{VCH}$, Weinheim

27. Jones CJ, Thornback JR (2007) Medicinal Applications of Coordination Chemistry. Royal Society of Chemistry: Cambridge, UK.

28. Mates JM (2000) Effects of antioxidant enzymes in the molecular control of reactive oxygen species toxicology. Toxicology 153: 83-104.

29. Mohareb RM, Zaki MY, Abbas NS (2015) Synthesis, anti-inflammatory and anti-ulcer evaluations of thiazole, thiophene, pyridine and pyran derivatives derived from and rostenedione. Steroids 98: 80-91.

30. Mostafa SI (2007) Mixed ligand complexes with 2-piperidine-carboxylic acid as primary ligand and ethylene diamine, 2,2'bipyridyl,1,10-phenanthroline and 2 (2'pyridyl) quinoxaline as secondary ligands: preparation, characterization and biological activity. Transition Metal Chemistry 32: 769-775.

31. Pravin N, Devaraji V, Raman N (2015) Targeting protein kinase and DNA molecules by diimine-phthalate complexes in antiproliferative activity. Int $\mathbf{J}$ Biol Macromol 79: 837-855.

32. Pravin N, Raman N (2014) Investigation of in vitro anticancer and DNA strap interactions in live cells using carboplatin type $\mathrm{Cu}$ (II) and $\mathrm{Zn}$ (II) metalloinsertors. Eur J Med Chem 85: 675-687.
33. Rajendiran V, Karthik R, Palaniandavar M, Stoeckli-Evans H, Periasamy VS, et al., (2007) Mixed-ligand copper (II)-phenolate complexes: effect of coligand on enhanced DNA and protein binding, cleavage, and anticancer activity. Inorg Chem 46: 82088221.

34. Siegel A, Siegel H, Siegel RKO (2007) Nickel and its Surprising Impact in Nature. Wiley, New York, USA.

35. Silva PP, Guerra W, Silveira JN, Ferreira AM, Bortolotto T, et al., (2011) Two new ternary complexes of copper(II) with tetracycline or doxycycline and 1,10phenanthroline and their potential as antitumoral: cytotoxicity and DNA cleavage. Inorg Chem 50: 6414-6424.

36. Sondhi SM, Singhal N, Verma RP, Arora SK, Dastidar SG (2001) Synthesis of hemin and prophyrin derivatives and their evaluation for anticancer activity. Indian $\mathbf{J}$ Chem B 40: 113-119.

37. Song WJ, Lin QY, Jiang WJ, Du FY, Qi QY, et al., (2015) Synthesis, interaction with DNA and antiproliferative activities of two novel $\mathrm{Cu}$ (II) complexes with norcantharidin and benzimidazole derivatives. Spectrochim Acta A Mol Biomol Spectrosc 137: 122-128.

38. Spinu C, Kriza A (2000) Co (II), Ni (II) and $\mathrm{Cu}$ (II) complexes of bidentate Schiff bases. Acta Chem Slov 47: 179-186.

39. Sun RWY, Che CM (2009) The anti-cancer properties of gold (III) compounds with dianionic porphyrin and tetradentate ligands. Coord Chem Rev 253: 1682.

40. Tabassum S, Amir S, Arjmand F, Pettinari C, Marchetti F, et al., (2013) Mixed-ligand $\mathrm{Cu}(\mathrm{II})$-vanillin Schiff base complexes; effect of coligands on their DNA binding, DNA cleavage, SOD mimetic and anticancer activity. Eur J Med Chem 60: 216-232.

41. Takamiya K (1960) Anti-tumour activities of copper chelates. Nature 185: 190-191.

42. Thompson KH, Orvig C (2003) Boon and bane of metal ions in medicine. Science 300: 936-939.

43. Turel I (2002) The interactions of metal ions with quinolone antibacterial agents. Coord Chem Rev 232: 27-47. 
44. Wang MZ, Meng ZX, Liu BL, Cai GL, Zhang CL, et al., (2005) Novel tumor chemotherapeutic agents and tumor radioimaging agents: potential tumor pharmaceuticals of ternary copper (II) complexes. Inorg Chem Commun 8: 368371.

45. Williams RJP, Frausto da Silva JJR (1997) The Natural Selection of the Chemical Elements, Clarendon Press, Oxford.

46. Yang CT, Moubaraki B, Murray KS, Vittal JJ (2003) Synthesis, characterization and properties of ternary copper (II) complexes containing reduced Schiff base N-(2hydroxybenzyl)- $\alpha$-amino acids and 1,10 phenanthroline. J Chem Soc Dalton Trans 880-889.

47. Yanga XB, Wanga Q, Huangb Y, Fua PH, Zhangc JS, et al., (2012) Synthesis, DNA interaction and antimicrobial activities of copper (II) complexes with Schiff base ligands derived from kaempferol and polyamines. Inorg Chem Commun 25: 5559.

48. Zianna A, Psomas G, Hatzidimitriou A, Lalia-Kantouri M (2015) Copper (II) complexes of salicylaldehydes and 2hydroxyphenones: synthesis, structure, thermal decomposition study and interaction with calf-thymus DNA and albumins. RSC Advances 5: 37495-37511.

49. Zuo J, Bi C, Fan Y, Buac D, Nardon C, et al., (2013) Cellular and computational studies of proteasome inhibition and apoptosis induction in human cancer cells by amino acid Schiff base-copper complexes. J Inorg Biochem 118: 83-93.

50. K. Pramanik, P. Malpaharia, A. J. Mota, E. Colacio, B. Das, F. Lloret and S. K. Chandra (2013), "Stepwise Formation of a Pentanuclear $\mathrm{Ni} 4 \mathrm{Cu}$ Heterometallic Complex Exhibiting a Vertex-Sharing Defective Double-Cubane Core and Diphenoxo and Phenoxo/azide Bridging Groups: A Magneto-Structural and DFT Theoretical Study", Inorg. Chem., 52, 3995-4001.

51. K. Pramanik, P. Malpaharia, E. Colacio, B. Das and S. K. Chandra (2018), "Octadentate flexible ligands as a platform for a variety of homo and heterometallic complexes containing diphenoxido and phenoxido/azido bridging groups: synthesis, structure and magnetic properties", New J. Chem., 42, 6332-6342.

52. K. Pramanik, P. Ghosh, D. Dey, P. Malpaharia, S. K. Chandra, S. K. Mukhopadhyay and P. Banerjee,"Chelator Probe with Exceptionally High Stokes Shift for Selective Detection of OAc with Red Emission: Application as a Biosensor" Chemistry Select, 2018, 3, 1151 - 1156.

53. P. Ghosh, K. Pramanik, S. Paul, P. Malpaharia, S. K. Chandra, S. K. Mukhopadhyay and P. Banerjee (2018), "Trace Level Recognition of $\mathrm{Zn}^{2+}$ and $\mathrm{Cd}^{2+}$ by Biocompatible Chemosensor inside Androecium, Diagnosis of Pick's Disease from Urine and Biomimetic $\beta$-Cell Exocytosis" ACS Appl. Bio Mater., 1, 683-692.

\section{How to cite this article:}

Pijush Malpaharia and Pandey, S. K. 2020. Dynamics of Transition Metal and their Application in Biomedical Industry. Int.J.Curr.Microbiol.App.Sci. 9(02): 2581-2589. doi: https://doi.org/10.20546/ijcmas.2020.902.294 